\title{
Risk factors for stroke and myocardial infarction in women in the United Kingdom as assessed in general practice: a case-control study
}

\author{
S G THOMPSON, * G GREENBERG, $\uparrow$ T W MEADE \\ From the Medical Research Council Epidemiology and Medical Care Unit, Northwick Park Hospital, Harrow
}

SUMMARY Data available in the United Kingdom through the Medical Research Council's General Practice Research Framework were recorded in a study of 603 women aged 45-69 with confirmed diagnoses of stroke or myocardial infarction, each matched by age with two controls. Current cigarette smoking and a family history of myocardial infarction were both strongly associated with the risk of stroke and myocardial infarction, with relative risks of $2.47(95 \%$ confidence interval 1.89 to 3.23 ) and $1.93(95 \%$ confidence interval 1.52 to 2.44$)$ respectively. The relative risks associated with past smoking decreased according to the length of time since stopping smoking. A family history of stroke was not significantly related to the risk of stroke or myocardial infarction. Single women had a lower risk of stroke and myocardial infarction than married women (relative risk 0.49 ), but parity, past use of oral contraceptives, and menopausal state were not significantly related to the risk of stroke and myocardial infarction in this study. Other characteristics that were identified as risk factors either for subsequent stroke or for myocardial infarction included not only hypertension, diabetes, and past histories of stroke and myocardial infarction, but also past histories of gynaecological cancer and of venous thrombosis. The association with venous thrombosis may indicate the importance of the haemostatic system in a common pathogenesis of venous thrombosis and myocardial infarction.

Most information on population risk factors for stroke and myocardial infarction is based on epidemiological studies of men, whose risk of cardiovascular disease is greater than that of women. Whereas the risks of fatal stroke are fairly similar in men and women, the risk of fatal ischaemic heart disease is substantially lower in women than in men at all ages, especially so under the age of about 65 years. About $40 \%$ of deaths in women of all ages and $>20 \%$ of those in women under the age of 65 , however, are attributed to ischaemic heart disease or cerebrovascular disease. ${ }^{1}$ Additional information on

\footnotetext{
*Present address and requests for reprints to Dr S G Thompson, Department of Clinical Epidemiology and General Practice, Royal Free Hospital Medical School, Rowland Hill Street, London NW3 2PF.
}

†Present address: Department of Health, Richmond House, 79 Whitehall, London SW1A 2NS. (The contents of this article represent the author's views alone and do not commit the Department of Health.)

Accepted for publication 16 February 1989 risk factors for stroke and myocardial infarction in women alone is therefore needed to provide a complete description of the important risk factors in the population as a whole.

In a case-control study of stroke and myocardial infarction in women in the United Kingdom, based in general practice, in which the focus was on the use of menopausal hormonal replacement therapy, ${ }^{2}$ information was also systematically collected on other potential risk factors. This paper describes the findings of the study with regard to these other factors.

\section{Patients and methods}

The methods have been described in detail elsewhere ${ }^{2}$; only the essential features are reported here. The study was based in 83 practices belonging to the Medical Research Council's General Practice Research Framework. ${ }^{3}$ Over a five and a half year period from 1981 to 1986 , cases of fatal and non-fatal stroke and myocardial infarction in white women aged 45 to 69 were investigated. Copies of additional 
information (such as hospital records and necropsy reports) were sought and the events classified by a single assessor using World Health Organisation criteria. ${ }^{45}$ For the purposes of statistical analysis, the 84 cases in the "possible" and the 275 cases in the "definite" categories of myocardial infarction were considered together, while suspected cases not meeting the criteria were excluded from the study. Of the total of 244 strokes finally accumulated in the study, $37(15 \%)$ were fatal; $94(26 \%)$ of the 359 myocardial infarctions were fatal.

Two controls were selected for each case. The controls were white women whose ages were within two years of the age of the case and who had the same general practitioner. We selected them by taking the first eligible older and first eligible younger patient working sequentially from the case patient through the age/sex register.

A research nurse in each practice obtained information from the woman (or her next of kin) by interview on marital status, parity (defined in terms of the number of live births), oral contraceptive use, cigarette smoking habit, family history of stroke or myocardial infarction, and menopausal state. Current smokers included women who had given up smoking in the same year as the case's stroke or myocardial infarction. A positive family history of stroke was recorded if the woman's father, mother, or any brother or sister had suffered a non-fatal or fatal stroke. A family history of myocardial infarction was similarly defined. A woman was classified as premenopausal if she was still menstruating, whether regularly or not. For a proportion of cases with a fatal event, some of these items of information were not available. Information on the medical history of all the women was taken from the medical notes and was thus complete.

Specially trained quality control nurses travelled to each of the 83 practices to check the procedure for selecting controls. Also, for 90 women in the study (two women in each of about half of the practices), the quality control nurse independently repeated the abstracting of the information on medical history from the medical notes. Discrepancies between the two nurses were most common for the past history of hypertension-in seven the quality control nurse recorded hypertension and the practice nurse did not, and the converse for eight. Of a total of 14 discrepancies, seven each for the past history of stroke and myocardial infarction, there were ten in which the quality control nurse recorded a positive history and the practice nurse did not, and the converse for four.

The relative risks of stroke and myocardial infarction were estimated by conditional maximum likelihood logistic regression ${ }^{6}$ appropriate for matched case-control studies. The $p$ values quoted are two sided and are given exactly for values between 0.2 and 0.001 .

\section{Results}

The risk of stroke and myocardial infarction was lower for single women than for married women (relative risk 0.49 , table 1 ). The relative risks of stroke and myocardial infarction separately according to marital state were not dissimilar $(p>0.2)$. The $17 \%$ of women who were nulliparous had a similar risk of stroke and myocardial infarction compared with parous women, the relative risk being $0.80(\mathrm{p}=$ $0.15)$ when unadjusted and $1.02(p>0.2)$ when adjusted for marital status.

Only two women were current users of oral contraceptives, that is at the time of stroke or myocardial infarction in the case. Of all the women, $9 \%$ had used oral contraceptives in the past. The average time since last use was 11 years. This use of oral contraceptives was not associated with the risk of stroke and myocardial infarction (relative risk 0.73 , $\mathrm{p}=0 \cdot 16$ ). The $6 \%$ of women classified as premenopausal did not have a significantly lower risk of stroke and myocardial infarction than postmenopausal women (relative risk $0.91, \mathrm{p}>0.2$ ).

The risk of stroke and myocardial infarction was

Table 1 Numbers of cases and controls according to marital state and estimates of relative risks of stroke and myocardial infarction

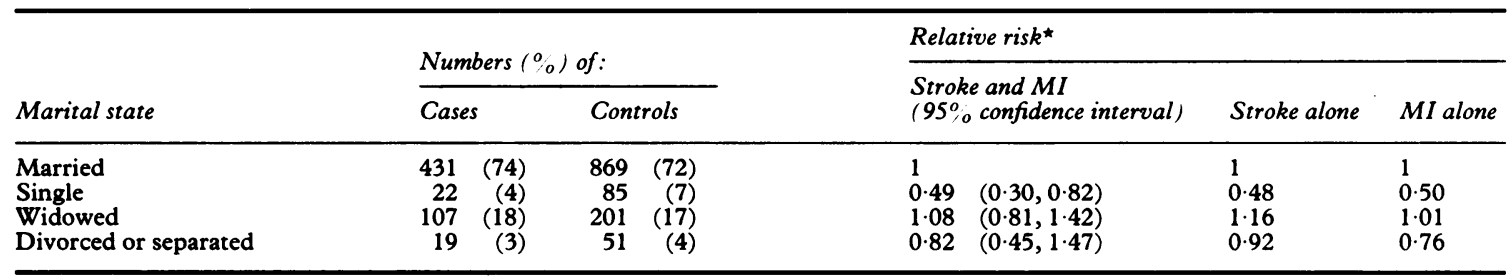

MI, myocardial infarction.

$\star$ Relative risks, relative to married women, take into account the matched design of the study. The relative risks for stroke and myocardial infarction combined are significantly different between the four categories of marital status $(\mathbf{p}=0.02)$. 
Table 2 Numbers of cases and controls and estimates of relative risk of stroke and myocardial infarction according to stated cigarette smoking habit and time since giving up in ex-smokers

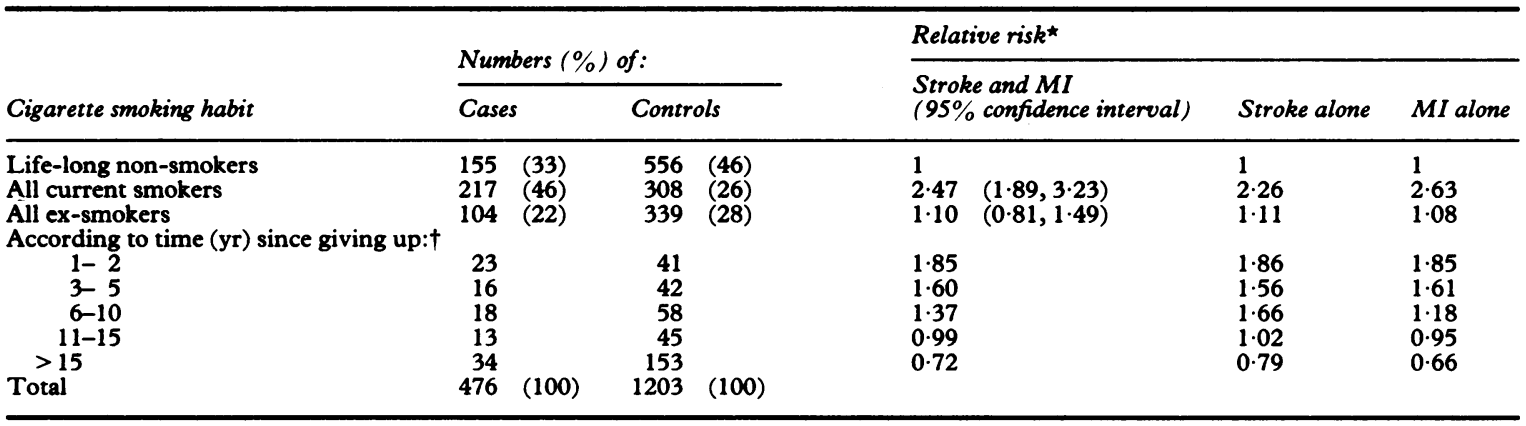

MI, myocardial infarction.

*Relative risks, relative to life-long non-smokers, take into account the matched design of the study.

tp Value for trend according to time since giving up for stroke and myocardial infarction combined, $p=0.001$. There was no significant difference $(p>0 \cdot 2)$ between the trends for stroke and myocardial infarction.

higher in current cigarette smokers than in those who had never smoked (relative risk $2.47, \mathrm{p}<0.001$, table 2). The relative risks for stroke and myocardial infarction separately were similar $(2.26$ and 2.63 respectively). There was a suggestion that the relative risks decreased with age (test for trend, $p=0.08$ ), with the relative risks in the five year age groups from 45 to 69 being $3 \cdot 7,5 \cdot 7,2 \cdot 5,2 \cdot 3$, and $2 \cdot 0$. Ex-smokers of cigarettes did not have an increased risk of stroke and myocardial infarction overall, but there was a gradient of risk according to the time since giving up smoking (table 2) such that the risk was highest in those who had given up most recently. The gradients of risk were very similar for each of stroke and myocardial infarction separately (table 2).

A family history of myocardial infarction was associated with the risk of stroke and myocardial infarction (relative risk 1.93, p $<0.001$ ) but a family history of stroke was not (relative risk $1 \cdot 10, p>0.2$, table 3). There was no evidence that a positive family history of one type of event (that is, stroke or myocardial infarction) related in particular to the risk of that type of event (table 3).

Table 4 shows the risks of stroke and myocardial infarction associated with the medical histories recorded. The relative risk was particularly high for past histories of stroke or subarachnoid haemorrhage, myocardial infarction, and diabetes. Past histories of stroke or subarachnoid haemorrhage and of hypertension were more strongly related to the subsequent risk of stroke than to the risk of myocardial infarction, the corresponding relative risks (table 4) being significantly different $(p=0.005$ and $p=0.03$ respectively). Past histories of myocardial infarction and of diabetes were similarly related to the subsequent risk of stroke and of myocardial infarction (both $p>0.2$ for a difference in relative risks). Though a past history of venous thrombosis did not seem important in the subsequent risk of stroke, it was related to the subsequent risk of myocardial infarction; the relative risk of 3.78 for subsequent myocardial infarction was significantly greater $(p=0.01)$ than that for stroke $(1 \cdot 16$, table 4$)$. A past history of cancer (endometrial, ovarian,

Table 3 Numbers of cases and controls with a family history of stroke or myocardial infarction in any first degree relative and estimates of relative risks of stroke and myocardial infarction

\begin{tabular}{|c|c|c|c|c|c|}
\hline \multirow{3}{*}{$\begin{array}{l}\text { Family history of: } \\
\text { Stroke }\end{array}$} & \multirow{3}{*}{$\begin{array}{l}\text { Risk of stroke } \\
\text { and/or MI }\end{array}$} & \multicolumn{2}{|c|}{ Numbers $(\%)$ of: } & \multirow{2}{*}{\multicolumn{2}{|c|}{$\begin{array}{l}\text { Relative risk } \\
(95 \% \text { confidence interval })\end{array}$}} \\
\hline & & Cases & Controls & & \\
\hline & & $\begin{aligned} 76 & (40) \\
90 & (35) \\
166 & (37)\end{aligned}$ & $\begin{array}{ll}163 & (33) \\
253 & (35) \\
416 & (35)\end{array}$ & $\begin{array}{l}1.33 \\
0.95 \\
1 \cdot 10\end{array}$ & $\begin{array}{l}(0.93,1.92) \\
(0.69,1.31) \\
(0.87,1.40)\end{array}$ \\
\hline Myocardial infarction & $\begin{array}{l}S \\
M I \\
S+M I\end{array}$ & $\begin{aligned} 88 & (46) \\
142 & (55) \\
230 & (51)\end{aligned}$ & $\begin{array}{ll}156 & (32) \\
268 & (38) \\
424 & (35)\end{array}$ & $\begin{array}{l}1.85 \\
1.99 \\
1.93\end{array}$ & $\begin{array}{l}(1 \cdot 28,2.66) \\
(1.46,2 \cdot 70) \\
(1.52,2.44)\end{array}$ \\
\hline
\end{tabular}

S, stroke; $\mathrm{MI}$, myocardial infarction.

^Relative risks, relative to the group of women without the corresponding family history; these take into account the matched design of the study. 
Table 4 Numbers of cases and controls with a recorded past history of various diseases and estimates of relative risk of stroke and myocardial infarction

\begin{tabular}{|c|c|c|c|c|c|c|}
\hline \multirow{3}{*}{$\begin{array}{l}\text { Past history of: } \\
\begin{array}{l}\text { Stroke and subarachnoid } \\
\text { haemorrhage }\end{array}\end{array}$} & \multirow{3}{*}{$\begin{array}{l}\text { Risk of stroke } \\
\text { and/or } M I\end{array}$} & \multicolumn{3}{|c|}{ Numbers ( $\%$ ) of: } & \multirow{2}{*}{\multicolumn{2}{|c|}{$\begin{array}{l}\text { Relative risk } \\
\text { ( } 95 \% \text { confidence interval) }\end{array}$}} \\
\hline & & \multicolumn{2}{|c|}{ Cases } & Controls & & \\
\hline & & $\begin{array}{r}57 \\
8 \\
65\end{array}$ & $\begin{array}{r}(23) \\
(2) \\
(11)\end{array}$ & $\begin{aligned} 9 & (2) \\
7 & (1) \\
16 & (1)\end{aligned}$ & $\begin{array}{c}14 \cdot 1 \\
2 \cdot 29 \\
8 \cdot 57\end{array}$ & $\begin{array}{l}(6.61,30.0) \\
(0.81,6.43) \\
(4.83,15.2)\end{array}$ \\
\hline $\begin{array}{l}\text { Hypertension (excluding in } \\
\text { pregnancy) }\end{array}$ & $\begin{array}{l}S \\
M I \\
S+M I\end{array}$ & $\begin{array}{l}155 \\
190 \\
345\end{array}$ & $\begin{array}{l}(64) \\
(53) \\
(57)\end{array}$ & $\begin{array}{ll}111 & (23) \\
186 & (26) \\
297 & (25)\end{array}$ & $\begin{array}{l}6 \cdot 09 \\
3 \cdot 53 \\
4 \cdot 41\end{array}$ & $\begin{array}{l}(4.15,8.95) \\
(2.61,4.76) \\
(3.48,5.58)\end{array}$ \\
\hline Myocardial infarction & $\begin{array}{l}S \\
M I \\
S+M I\end{array}$ & $\begin{array}{l}17 \\
69 \\
86\end{array}$ & $\begin{array}{l}(7) \\
(19) \\
(14)\end{array}$ & $\begin{array}{rr}2 & (<1) \\
8 & (1) \\
10 & (1)\end{array}$ & $\begin{array}{l}17 \cdot 0 \\
19 \cdot 5 \\
19 \cdot 0\end{array}$ & $\begin{array}{l}(3 \cdot 81,75 \cdot 8) \\
(8 \cdot 82,43 \cdot 1) \\
(9 \cdot 40,38 \cdot 2)\end{array}$ \\
\hline Diabetes & $\begin{array}{l}S \\
M I \\
S+M I\end{array}$ & $\begin{array}{l}27 \\
37 \\
64\end{array}$ & $\begin{array}{l}(11) \\
(10) \\
(11)\end{array}$ & 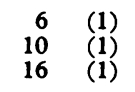 & $\begin{array}{c}10 \cdot 5 \\
9 \cdot 96 \\
10 \cdot 2\end{array}$ & $\begin{array}{l}(3 \cdot 97,27 \cdot 9) \\
(4 \cdot 36,22 \cdot 8) \\
(5 \cdot 42,19 \cdot 1)\end{array}$ \\
\hline Venous thrombosis & $\begin{array}{l}S \\
M I \\
S+M I\end{array}$ & $\begin{array}{l}15 \\
29 \\
44\end{array}$ & $\begin{array}{l}(6) \\
(8) \\
(7)\end{array}$ & $\begin{array}{ll}26 & (5) \\
16 & (2) \\
42 & (3)\end{array}$ & $\begin{array}{l}1 \cdot 16 \\
3 \cdot 78 \\
2 \cdot 14\end{array}$ & $\begin{array}{l}(0 \cdot 60,2 \cdot 23) \\
(2 \cdot 00,7 \cdot 15) \\
(1 \cdot 38,3 \cdot 32)\end{array}$ \\
\hline $\begin{array}{l}\text { Arterial thrombosis (other } \\
\text { than stroke, } \mathrm{SAH} \text {, or } \mathrm{MI}) \dagger\end{array}$ & $\mathbf{S}+\mathbf{M I}$ & 19 & (3) & (1) & $4 \cdot 22$ & $(1.88,9.48)$ \\
\hline Cancer $\ddagger$ & $\begin{array}{l}S \\
M I \\
S+M I\end{array}$ & $\begin{array}{l}10 \\
19 \\
29\end{array}$ & $\begin{array}{l}(4) \\
(5) \\
(5)\end{array}$ & $\begin{array}{l}(6) \\
(2) \\
(4)\end{array}$ & $\begin{array}{l}0 \cdot 73 \\
2 \cdot 24 \\
1 \cdot 32\end{array}$ & $\begin{array}{l}(0.35,1.56) \\
(1 \cdot 15,4.36) \\
(0.82,2 \cdot 14)\end{array}$ \\
\hline
\end{tabular}

S, stroke; MI, myocardial infarction; SAH, subarachnoid haemorrhage.

* Relative risks, relative to the group of women without a past history of the corresponding disease; these take into account the matched design of the study. All the relative risks (for stroke + MI together) are statistically highly significant (p < 0.001 ), except for the fou cancers $(p>0.2)$.

tToo few for subdivision.

†Endometrial, ovarian, cervical, or breast cancer.

cervical, or breast) was significantly related to the risk of myocardial infarction, but not to the risk of stroke (table 4).

When all the medical histories were considered simultaneously in a multivariate analysis, the estimated relative risks were generally slightly less than those presented in table 4 because of the interrelations between them. While the risk associated with a past history of arterial thrombosis (excluding stroke, subarachnoid haemorrhage, and myocardial infarction) was no longer statistically significant in the multivariate analysis, the risks associated with all the other past histories remained strong, with relative risks similar to those shown in table 4.

\section{Discussion}

This study provides estimates of the relative risk of stroke and myocardial infarction in women associated with various factors that are easily assessed in general practice in the United Kingdom. These risk estimates are quite precise, being based on 603 cases of stroke and myocardial infarction made available through the collaboration of a large number of group general practices over an extended period of time.
Because this was a case-control study, it was not appropriate to measure a number of other risk factors, such as serum cholesterol, weight, and blood pressure, because they might have been changed by the acute stroke or myocardial infarction itself.

Since the interviews and the retrieval of information from the medical notes were performed by practice nurses who knew whether the woman was a case or control, some bias is possible. Because the main emphasis of the study was on the use of hormonal replacement therapy, however, it seems likely that the data reported in this paper would have been collected with the same thoroughness for controls as for cases. Where the abstraction of data from the medical notes was checked by an independent quality control nurse, there was no apparent tendency for the practice nurse to over-report positive medical histories in case patients. It is possible that the information on family history, which was obtained by interview, may have led to estimated relative risks slightly inflated by recall bias.

The present study suggests that single women have a lower risk of stroke and myocardial infarction than married women. These findings are supported by the Framingham Study which found that among clerical workers, single women had lower risks of 
coronary heart disease than married women who had raised children. ${ }^{7}$ Other studies have suggested that women who are widowed, divorced, or separated are more likely to develop coronary heart disease, ${ }^{8}$ but this was not seen in the present study.

Only a few studies found an association of parity with the risk of coronary heart disease in women. Where an association was found, multiparous women had a higher risk of coronary heart disease than nulliparous women, ${ }^{910}$ but most studies did not find such an association. ${ }^{11}$ In the present study, no association between parity and the risk of stroke and myocardial infarction was evident, especially after adjustment for marital state. Only $11 \%$ of the married women were nulliparous, so that marital state and parity were somewhat interrelated. The potential confounding effects of both age and marital state need to be carefully controlled in studies on parity.

Whereas it is generally found that current oral contraceptive use is associated with a threefold to fourfold increase in the risk of myocardial infarction and stroke, ${ }^{12}$ the effects of oral contraceptives after their use has ceased are more uncertain. An increased risk of stroke, but not myocardial infarction, lasting more than six years after cessation of oral contraceptive use has been suggested. ${ }^{13}$ In one case-control study of myocardial infarction, no association with past oral contraceptive use was found overall ${ }^{14}$; however, an increased risk was evident in those past users of oral contraceptives in whom the duration of use was greater than five years. ${ }^{15}$ In the present study, we found no significant association of the past use of oral contraceptives with the risk of stroke and myocardial infarction; the low rate of past oral contraceptive use ( $9 \%$ of the women) precluded the useful subdivision of the data according to time since last use and type of cardiovascular event. Possibly, in a similar way, the low proportion of women who were premenopausal may have prevented the demonstration of a greater cardiovascular risk in postmenopausal than in premenopausal women of the same age, which has been found by others. ${ }^{16} 17$

In the present study, women who smoked cigarettes had about 2.5 times the risk of stroke and myocardial infarction compared with women who had never smoked. This is a consistent finding in studies of women ${ }^{18}$ as well as in studies of men. In the Medical Research Council's Mild Hypertension Trial, women had greater relative risks associated with smoking than men, for both stroke and myocardial infarction. ${ }^{19}$ The finding of a decreasing relative risk with increasing age is supported by other studies of women ${ }^{20}$ as well as those of men. Overall, exsmokers had only a marginally higher risk of stroke and myocardial infarction than women who had never smoked. Subdivision of the data according to time since giving up smoking, however, showed that those who had given up in the past five years still maintained a substantial proportion of the excess risk attributable to current smoking. No excess risk was evident in those women who had given up for $\geqslant 10$ years. Other studies of coronary heart disease showed similar results in men. ${ }^{21}$ The mechanism by which smoking causes coronary heart disease thus has long term effects which are not rapidly reversible on giving up smoking.

Family history is an important risk factor for coronary heart disease; studies in general have shown about a twofold risk associated with a parental history of coronary heart disease..$^{22-24}$ Similar or more extreme results have been found for siblings. In the present study we did not know the age at which a parent or sibling developed a myocardial infarction or stroke, and the family history considered was that for any parent or sibling. There was a notable distinction between the relevance of family histories of myocardial infarction and that of stroke; while a family history of myocardial infarction was similarly related to the risk of both stroke and myocardial infarction in the index subject, a family history of stroke was not apparently related to either. This is despite the fact that hypertension, and to a lesser extent smoking habits, have tendencies to aggregate in families, ${ }^{22}$ and that a family history of stroke has been found to be related to the risk of stroke in women in a previous study. ${ }^{25}$

The relations seen between past medical history and the risk of stroke and myocardial infarction (table 4) are mainly expected, at least in qualitative terms. Both hypertension and a past history of stroke or subarachnoid haemorrhage were more strongly related to the risk of stroke than to the risk of myocardial infarction. In contrast, past histories of diabetes and myocardial infarction were related similarly to the risk of myocardial infarction and of stroke. Diabetes is one of the risk factors for coronary heart disease that is more important in women than men, with the result that women with diabetes have a risk of myocardial infarction similar or only slightly lower than that of diabetic men. ${ }^{26}{ }^{27}$ So while diabetes is associated with about a twofold increase in coronary heart disease risk in men, ${ }^{28}$ the relative risk for women in this study was tenfold. Although the past histories considered were somewhat interrelated, their independent associations with risk (as expressed in a multivariate analysis) remained important, and their importance was only slightly diminished as compared with when each past history was considered singly.

The slightly increased risk of myocardial infarction seen in this study associated with a past history 
of gynaecological cancers does not have an obvious explanation; allowance for smoking or other risk factors did not remove the apparent excess risk. It may be that the relation between haemostasis and malignancy ${ }^{29}$ is also expressed in an increased risk of myocardial infarction in women with a past history of cancer.

The importance of a past history of venous thrombosis for the future risk of myocardial infarction found in the present study has not been described before. The most obvious common risk factors for venous and arterial events are haemostatic variables. ${ }^{3031}$ This finding supports the hypothesis that raised concentrations of certain coagulation factors or decreased fibrinolytic activity may predispose to thrombosis, there being evidence for this in both population studies ${ }^{32}$ and clinical studies. ${ }^{33-35}$

We thank the doctors and nurses in the Medical Research Council's General Practice Research Framework who participated in this study and Professor Hugh Tunstall-Pedoe who undertook the substantial task of assessing the cases of stroke and myocardial infarction. We also thank Pat O'Kelly for the extra clerical and data-processing work in the study.

\section{References}

1 Office of Population Censuses and Surveys. Mortality statistics by cause for England and Wales, 1985. Series DH2 no. 12. London: HMSO, 1987.

2 Thompson SG, Meade TW, Greenberg G. The use of hormonal replacement therapy and the risk of stroke and myocardial infarction in women. $J$ Epidemiol Community Health, 1989;43 (in press).

3 Medical Research Council's Working Party on mild to moderate hypertension. Randomized controlled trial of treatment of mild hypertension: design and pilot trial. Br Med J 1977;i:1437-40.

4 World Health Organization Regional Office for Europe. Myocardial infarction community registers. (Public Health in Europe No. 5). Copenhagen: World Health Organization, 1976.

5 Aho $\mathrm{H}$, Harmsen $\mathrm{P}$, Hatano S, Marquardsen J, Smirnov VE, Strasser T. Cerebrovascular disease in the community; results of a WHO collaborative study. Bull WHO 1980;58:113-30.

6 Breslow NE, Day NE. Statistical methods in cancer research. Volume 1: The analysis of case-control studies. Lyon: International Agency for Research on Cancer, 1980.

7 Haynes SG, Feinleib M. Women, work and coronary heart disease: prospective findings from the Framingham Heart Study. Am J Public Health 1980;70: 133-41.

8 Haynes SG. Type A behaviour, employment status, and coronary heart disease in women-a review. In: Oliver MF, Vedin A, Wilhelmsson C, eds. Myocar- dial infarction in women. Edinburgh: Churchill Livingstone, 1986:66-92.

9 Oliver MF. What is the difference between men and $\stackrel{C}{-}$ women? In: Oliver MF, Vedin A, Wilhelmsson C, $\overrightarrow{\overline{\vec{F}}}$ eds. Myocardial infarction in women. Edinburgh:Churchill Livingstone, 1986:215-21.

10 Wilkelstein W Jr, Stenchever MA, Lilienfeld AM. $\frac{\bar{\sigma}}{\omega}$ Occurrence of pregnancy, abortion, and artificial $\frac{\sigma}{\sigma}$ menopause among women with coronary artery $\unrhd$ disease: a preliminary study. J Chronic Dis 1958;7: 273-86.

11 Bonnar J. Effects of physiological changes in sex. hormones on potential coronary risk factors. In: $\overrightarrow{\vec{\omega}}$ Oliver MF, ed. Coronary heart disease in young women. $\stackrel{\omega}{\omega}$ Edinburgh: Churchill Livingstone, 1978: 107-17.

12 Stadel BV. Oral contraceptives and cardiovascular 9 disease. $N$ Engl J Med 1981;305:612-8 and 672-7.

13 Royal College of General Practitioners' Oral Contraception Study. Incidence of arterial disease amongst $\omega$ oral contraceptive users. $J R$ Coll Gen Pract 1983; 윽 33:75-82.

14 Slone D, Shapiro S, Kaufman DW, Rosenberg L, Miettinen OS, Stolley PD. Risk of myocardial infarction in relation to current and discontinued use of oral $\overrightarrow{0}$ contraceptives. $N$ Engl J Med 1981;305:420-4.

15 Shapiro S. Continued effects of oral contraceptives after. cessation of treatment. In: Oliver MF, Vedin A, Wilhelmsson C, eds. Myocardial infarction in women. Edinburgh: Churchill Livingstone, 1986:119-29.

16 Gordon T, Kannel WB, Hjortland MC, McNamara PM. Menopause and coronary heart disease: The $\frac{2}{\mathbb{Q}}$ Framingham Study. Ann Intern Med 1978;89: 을 157-61.

17 Colditz GA, Willett WC, Stampfer MJ, Rosner B, Speizer FE, Hennekens $\mathrm{CH}$. Menopause and the risk of coronary heart disease in women. $N$ Engl $J$ Med 1987;316:1105-10.

18 Doll R, Gray R, Haffner B, Peto R. Mortality in relation to smoking: 22 years' observations on female British doctors. Br Med J 1980;i:967-71.

19 Medical Research Council Working Party. Stroke and: coronary heart disease in mild hypertension: risk factors and the benefit of treatment. $\mathrm{Br} \mathrm{Med} J 1988$; 296:1565-70.

20 Rosenberg L, Shapiro S, Kaufman DW, Slone D, Miettinen OS, Stolley PD. Cigarette smoking in relation to the risk of myocardial infarction in young women. Modifying influence of age and predisposing $\mathrm{N}$ factors. Int $J$ Epidemiol 1980;9:57-63.

21 Cook DG, Shaper AG, Pocock SJ, Kussick SJ. Giving 유 up smoking and the risk of heart attacks. Lancet 1986; $\mathfrak{W}$ ii: $1376-80$.

22 Rissanen AM. Familial occurrence of coronary hearte

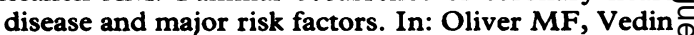
A, Wilhelmsson C, eds. Myocardial infarction in $\stackrel{\oplus}{+}$ women. Edinburgh: Churchill Livingstone, 1986: 18-33.

23 Phillips AN, Shaper AG, Pocock SJ, Walker M. Parental death from heart disease and the risk of heart $\frac{}{\Phi}$ attack. Eur Heart $J$ 1988;9:243-51.

24 Colditz GA, Stampfer MJ, Willet WC, Rosner B, 
Speizer FE, Hennekens $\mathrm{CH}$. A prospective study of parental history of myocardial infarction and coronary heart disease in women. Am J Epidemiol 1986;123: 48-58.

25 Khaw K, Barrett-Connor E. Family history of stroke as an independent predictor of ischaemic heart disease in men and stroke in women. Am J Epidemiol 1986;123: 59-66.

26 Marks $\mathrm{HH}$, Krall LP. Onset, course, prognosis and mortality in diabetes mellitus. In: Marble A, White P, Bradley RF, Krall LP, eds. Joslin's diabetes mellitus. 11 th ed. Philadelphia: Lea and Febiger, 1971:209-54.

27 Fuller JH, Head JA. Factors related to mortality in 5600 diabetic patients from 12 international centres [Abstract]. Diabetologia 1986;29:539a.

28 Shaper AG, Pocock SJ, Phillips AN, Walker $M$. Identifying men at high risk of heart attacks: strategy for use in general practice. $\mathrm{Br}$ Med $J$ 1986;293:474-9.

29 Muszbek L, ed. Haemostasis and cancer. Florida: CRC Press, 1987.

30 Ducimetiere P, Richard JL, Pequignot G, Warnet JM.
Varicose veins: a risk factor for atherosclerotic disease in middle-aged men? Int $J$ Epidemiol 1981;10:329-35.

31 Meade TW, Brozovic M, Chakrabarti RR, et al. Haemostatic function and ischaemic heart disease: principal results of the Northwick Park Heart Study. Lancet 1986;ii:533-7.

32 Meade TW. Clotting factors and ischaemic heart disease: the epidemiological evidence. In: Meade TW, ed. Anticoagulants and myocardial infarction: a reappraisal. Chichester: Wiley, 1984.

33 Rocha E, Alfaro MJ, Paramo JA, Canadell JM. Preoperative identification of patients at high risk of deep venous thrombosis despite prophylaxis in total hip replacement. Thromb Haemost 1988;59:93-5.

34 Boyer C, Wolf M, Rothschild C, et al. An enzyme immunoassay (ELISA) for the quantitation of human factor VII. Thromb Haemost 1986;56:250-5.

35 Davies JA. Detection of a pre-thrombotic state. In: Bloom AL, Thomas DP, eds. Haemostasis and thrombosis. 2nd ed. Edinburgh: Churchill Livingstone, 1987:721-38. 